\title{
Satélites, territorio y cultura: ARSAT y la geopolítica popular
}

\section{Daniel Blinder}

Centro de Estudios de Historia de la Ciencia y la Técnica José Babini, Laboratorio de Investigación en Ciencias Humanas, Universidad Nacional de San Martín, Argentina.

\author{
Diego Hurtado de Mendoza \\ Centro de Estudios de Historia de la Ciencia y la Técnica José Babini, Laboratorio de \\ Investigación en Ciencias Humanas, Universidad Nacional de San Martín, Argentina.
}

Recibido: 30 de mayo de 2018. Aceptado: 4 de diciembre de 2018.

\section{Resumen}

Analizamos desde una perspectiva geopolítica crítica la política de comunicación satelital durante dos períodos delimitados por las trayectorias de las empresas NahuelSat y ARSAT. A partir del lugar específico de Argentina en la estructura jerárquica de la economía capitalista como país semiperiférico, nos enfocamos en las transformaciones cultural y geopolítica que acompañó las puestas en órbita de los dos satélites geoestacionarios ARSAT 1 y 2 -percibidas hoy como hitos tecnológicos nacionales-, el posicionamiento de Argentina como integrante de un selecto club de naciones, y el componente de geopolítica popular -constelación de imágenes y relatos que vinculan a estos satélites a un logro colectivo- que emerge de este proceso. Concluimos que, como contraste del pasado reciente de desintegración territorial, desindustrialización y pobreza que derivó en la crisis terminal de 2001, el programa ARSAT impulsa un proceso de resignificación del territorio argentino, de sus representaciones y los imaginarios asociados a las nociones de espacialidad, extensión y soberanía.

\section{Satellites, territory and culture: ARSAT and popular geopolitics}

\begin{abstract}
We analyze from a critical geopolitical perspective the policy of satellite communication during two periods delimited by the trajectories of firms NahuelSat and ARSAT. Regarding the specific position occupied by Argentina within the hierarchical structure of the capitalist economy as a semiperipheral country, we focused on the cultural and geopolitical transformations that accompanied the putting into orbit of the two
\end{abstract}

Palabras clave

ARSAT

Satélites Geostacionarios

Geopolítica

Semiperiferia

Palavras-chave

\section{ARSAT}

Satélites geoestacionários Geopolítica Semiperiferia

Keywords

ARSAT

Geostationary Satellites Geopolitics Semi-periphery 
Argentine geostationary satellites ARSAT 1 and 2 -which are perceived today as national technological milestones-, the positioning of Argentina as a member of a select club of nations, and the component of popular geopolitics - as a constellation of images and stories that link these satellites to a collective achievement- that emerges from this process. We conclude that, as a contrast with the recent past of territorial disintegration, deindustrialization, and poverty that led to the 2001 terminal crisis, the ARSAT program promotes a process of Argentine territory resignification, its representations, and the imageries associated with the notions of spatiality and sovereignty.

\section{Introducción}

A diferencia de una concepción puramente mercantil de las políticas de comunicación satelital dominantes en América Latina durante la década de 1990, la trayectoria que se inicia en Argentina con la creación, en 2006, de la empresa estatal ARSAT y la decisión de que los satélites geoestacionarios que deben ocupar las dos posiciones orbitales asignadas a la Argentina sean construidos por empresas nacionales incorpora dimensiones de política industrial y tecnológica que transforman las comunicaciones satelitales en sector estratégico. Si además se considera la necesidad de negociar la puesta en órbita de los satélites -la Argentina no cuenta con el cohete inyector, pero desarrolló una diplomacia perdurable, formal e informal, que le ha permitido llegar a este cometido desde la Guyana Francesa- y que, una vez puestos en órbita, además de la contratación de servicios, ARSAT se propone también avanzar sobre la integración territorial, entonces resulta evidente el componente geopolítico crucial que surge y acompaña la evolución de esta empresa pública.

Incluso, el logro tecnológico que significó la fabricación de dos satélites geoestacionarios en un país semiperiférico como Argentina y su impacto sobre el imaginario social hace posible hablar de una geopolítica popular -como iconografía, constelación de imágenes y relatos que vinculan la puesta en órbita de los satélites a un logro colectivo- que resignificó en alguna medida la percepción social del posicionamiento del país en el sistema internacional. En especial, la representación del propio país como uno de los integrantes de un selecto club de naciones capaz de fabricar satélites geoestacionarios contrastaba con la memoria colectiva de un pasado reciente de desintegración territorial, extranjerización de la economía y desindustrialización, pobreza y migración de científicos y tecnólogos, proceso que alcanzó su máxima expresión con la crisis del 2001 y que los gobiernos de Néstor Kirchner y Cristina Fernández (2003-2015) se propusieron revertir.

En este artículo se analizarán documentos institucionales, técnicos y periodísticos sobre la política de ARSAT a partir de una perspectiva geopolítica crítica. En una primera parte se introduce la noción de geopolítica popular y se la relaciona con el impulso de políticas tecnológicas en contexto de país semiperiférico. En una segunda parte se explicará qué es y cómo se desarrolló la política de comunicaciones satelitales en Argentina desde la década de 1990 y la ruptura con el paradigma neoliberal que marca la creación de ARSAT en 2006 con el objetivo de comprender cómo una política industrial y tecnológica en un sector reservado a las economías centrales influyó sobre la recuperación de una representación integrada del territorio nacional. Finalmente, se estudia el fenómeno ARSAT en su dimensión político/cultural y en la conformación de una geopolítica popular relacionada con la noción de soberanía tecnológica.

La geopolítica es el estudio de la acción, los efectos y los discursos de la política con anclaje territorial. Agnew y Stuart (1995:15) describen al orden geopolítico como "reglas rutinizadas, instituciones, actividades y estrategias a través de las cuales la economía 
política ha operado en diferentes períodos". El discurso geopolítico trata sobre "cómo es leído y escrito el mundo, el orden y las prácticas" (Agnew y Stuart, 1995:46) en el desenvolvimiento de la política. A su vez, la cuestión del orden geopolítico refiere a los elementos geográficos y jerárquicos que condicionan las relaciones económicas y políticas. En este sentido, cualquiera sea este orden, siempre trata de "una mixtura de cohesión y conflicto entre actores, un sistema de gobernanza organizado que define los actores, las reglas, los principios de interacción, y concepciones compartidas entre los actores acerca del comercio, la fuerza y la diplomacia (Agnew y Stuart, 1995:15-16). ${ }^{1}$ La geopolítica también proporciona "formas de mirar el mundo y es altamente visual", sus discursos apelan a "mapas, tablas y fotografías" para construir representaciones del paisaje global. Caracterizaciones geográficas y metáforas como "cortina de hierro", "Tercer Mundo", o "estado canalla" son términos "inherentemente geográficos porque los lugares son identificados y etiquetados a partir de estos términos" (Dodds, 2007: 4) e informan a los decisores de política internacional. Podríamos extender esta lista con términos como "país proliferador" o, incluso, "país en desarrollo", donde los factores industrial y tecnológico son decisivos. ${ }^{2}$

Cada metáfora informa sobre características de un lugar, su ubicación, y en oposición a qué. La noción de "Estado central" remite a una representación de país con una economía desarrollada, diversificada, tecnológicamente avanzada y, por lo tanto, influyente en el sistema internacional. Un Estado tecnológicamente desarrollado supone capacidades para intervenir en la determinación de las "reglas de juego" a escala global: un sistema productivo y financiero - en general, también militar- con capacidades de respuesta para avalar su posición y un sistema de alianzas que, en conjunto, garantizan un lugar en la jerarquía de Estados para, por ejemplo, asegurar la provisión de recursos naturales y la apertura de mercados para sus productos y servicios. Por el contrario, un Estado periférico no posee estas características. Y un Estado semiperiférico como la Argentina es aquel que tiene cierta capacidad industrial y tecnológica, además de infraestructura y servicios razonables que, en conjunto, suponen algún grado de desarrollo (Wallerstein, 2005), aunque baja o nula influencia en la arena internacional.

La geopolítica, a los efectos del presente trabajo, puede ser producida por la academia, institutos asociados a sectores de la política o la economía, o intelectuales (geopolítica formal); por gobiernos o burocracias (geopolítica práctica); o por medios de comunicación, cine, o ficciones noveladas (geopolítica popular). Así, desde distintos ámbitos se producen distintas representaciones geopolíticas sobre el lugar de un "nosotros" y de "otros" (Dodds, 2007). Estas formas de enfocar la geopolítica nos permiten aplicar tres marcos de análisis distintivos para enfocar el análisis de caso aquí propuesto en su relación con el territorio y el orden geopolítico.

\section{Geopolítica y representaciones ficcionadas}

El término "orden geopolítico", según Jason Dittmer, se ha referido en el pasado a los esquemas diagramados de la distribución del poder entre varios estados. No obstante, "tales enfoques de los órdenes geopolíticos tienden a acentuar la estabilidad y la estructura, en lugar de los discursos y las actuaciones que dan el efecto de estabilidad y estructura" (Itálica en el original). Los órdenes geopolíticos son historias que se cuentan y se escuchan, "producen el mundo en el que vivimos, le asignan valores a algunos lugares e ignoran otros" (Dittmer, 2013:124). ${ }^{3}$ Siguiendo a este autor en su propuesta de enfocar componentes ficcionales de las representaciones geopolíticas, la televisación de la puesta en órbita del satélite ARSAT 1, de la cuenta regresiva y el despegue del cohete inyector, junto con la identificación del evento como un paso hacia la soberanía tecnológica, fueron parte crucial en la construcción de un nuevo imaginario. Para un
1. Las instituciones formales internacionales son regímenes internacionales que regulan el comportamiento de los Estados, códigos de conducta, y prácticas cuyo objetivo es el control la praxis de un Estado-Nación.

2. Sobre la metáfora de "país proliferador" aplicada al caso argentino, puede verse Hurtado (2015).
3. Dittmer (2013) estudia los personajes y las historias de súper héroes en las revistas de comics como representaciones geopolíticas. Los orígenes del superhéroe del comic norteamericano se remontan a la crisis de la década de 1930. Las personalidades de estos personajes, concebidas para denotar moralidad, autoridad y poder, los transformaron en arquetipos de héroes nacionales (Dittmer, 2013:22) 
perfil de país como la Argentina, que en su pasado reciente había padecido un ciclo de endeudamiento externo sin precedentes que llevó a una crisis de inmensas proporciones en 2001, que arrastraba un proceso de extranjerización, desindustrialización y empobrecimiento, este hito tecnológico se trató de presentar como factor de resignificación del lugar de la Argentina en el orden geopolítico.

En alusión a la noción de "ontología espacial", Agnew y Corbridge plantean que términos como "centro y periferia, territorio y localización se han vuelto cada vez más populares como locuciones en las ciencias sociales y las humanidades". Sin embargo, agregan, la terminología geográfica se ha tornado "metafórica y descriptiva en lugar de ontológica". Las nociones de "territorio" y "localización" evocan imágenes abstractas de diferenciales de poder y bienestar, aunque estas abstracciones que se consideran que producen estos diferenciales llevan enraizados en ellos supuestos implícitos acerca de cómo el espacio media en los procesos sociales y económicos (1995:13-14). Mientras que las capacidades diferenciales de los Estados de acceder y dominar tecnologías estratégicas integra el núcleo de estos supuestos implícitos, ${ }^{4}$ cuando un país no central avanza sobre estas capacidades desestabiliza el orden geopolítico y la abstracción es desplazada por la disputa ontológica: un país no central camino a dominar una tecnología estratégica aparece como una anomalía. Así, la cuestión del orden geopolítico refiere al cruce de elementos geográficos y jerárquicos.

Finalmente, el elemento jerárquico del orden geopolítico, que se desenvuelve dentro de un marco de reglas escritas y no escritas, se define por una distribución global de relaciones capital-trabajo -o división internacional del trabajo-, esto es, quién produce qué cosas (y en qué condiciones), quién se beneficia (y con qué márgenes) y cómo se determinan las condiciones de intercambio y los flujos de valor. Este artículo gira en torno a la cuestión de qué Estados tienen (o pueden tener) la capacidad de desarrollar artefactos del tipo de los satélites geoestacionarios, y qué Estados deben comprar los servicios de uno ajeno.

En el caso argentino, la empresa ARSAT altera la jerarquía como bien económico y tecnológico cuyas capacidades de producción, gestión y uso se espera que estén concentradas en las economías centrales. Así, la decisión de esta empresa pública de desarrollar sus propios satélites geoestacionarios como respuesta al fracaso de una empresa de capitales extranjeros deberá coevolucionar con la resignificación de su geopolítica en sus dimensiones formal, práctica y popular. Desde la perspectiva de la Argentina, en el plano cultural estas nuevas capacidades son portadoras de resignificaciones del imaginario geopolítico social en la dirección de una autopercepción como colectivo nacional que -a partir de valores como el orgullo o la autoestima- supone la capacidad del país de sobreponerse a un pasado reciente sombrío para alcanzar metas relevantes.
4. Si bien, de acuerdo con la caracterización del economista heterodoxo coreano Ha-Joon Chang, "el desarrollo económico consiste en adquirir y dominar tecnologías avanzadas" (2008: 81), es imposible pensar las políticas tecnológicas sin la variable externa y sus condicionantes, como los procesos de negociación, las regulaciones siempre desfavorables para las periferias y, por lo tanto, los inevitables conflictos. Por otra parte, si el orden mundial es institucional, entonces las políticas que se proponen impulsar procesos de cambio tecnológico deberán considerar las formas institucionales vigentes en un momento de la historia, que reflejan y canalizan relaciones específicas de poder (Blinder, 2017b). Una discusión sobre instituciones y orden global neoliberal, puede verse en Chang (2007).

\section{Dinamismo económico, supremacía tecnológica y "reglas de juego"}

Entender la política es entenderla en clave geográfica, puesto que el espacio se manifiesta siempre como áreas en disputa. "El espacio nunca constituye un mero escenario donde se desarrollan los acontecimientos: ninguna disposición espacial tiene nada de neutral" (Taylor y Flint, 2002:42). Entendemos, por lo tanto, a la geopolítica como el estudio de la distribución geográfica de poder entre los Estados, tanto como los supuestos, designaciones e interpretaciones geográficas que intervienen en la política en todas las escalas espaciales (Agnew, 2005a:159; Taylor y Flint, 2002:416).

No cualquier actor a escala global puede producir aquello que quiere, ya sea por limitaciones materiales -inversiones, bienes de capital, saberes técnicos, competencias 
organizacionales, etc.-, o por los límites que impone el mismo sistema, sus instituciones, $\mathrm{u}$ otros actores capaces de influir, restringir, cercenar el desarrollo. De acuerdo a Immanuel Wallerstein, el sistema-mundo es un "modo económico [que] se basa en el hecho de que los factores económicos operan en el seno de una arena mayor de lo que cualquier entidad política puede controlar totalmente" (Wallerstein, 2005:491), que va más allá de las estructuras de los Estados y conforma espacios centrales, semiperiféricos y periféricos. El lugar político dominante de los Estados centrales en la jerarquía del sistema internacional se define por su dinamismo económico y su supremacía tecnológica. Son periféricos los Estados-Nación que no tienen poder económico ni político y, por lo tanto, son poco relevantes en la economía y en el sistema interestatal, y aportan al mismo principalmente materias primas y productos primarios. Los países semiperiféricos son aquellos de la periferia con cierta capacidad industrial y tecnológica y, por lo tanto, con algo más de relevancia política en aspectos restringidos del sistema interestatal, aunque en la medida en que aspiran a desarrollar capacidades que no le son asignadas en la división internacional del trabajo y que se consideran propias de los países centrales -como los satélites geoestacionarios, en este artículo-, son percibidos como componentes desestabilizadores.

La semiperiferia combina rasgos del centro y de la periferia, con un Estado activo en las políticas de desarrollo, esto es, con algún nivel de intervención en la elaboración de incentivos y cierta capacidad de disciplinamiento de algunos actores económicos e, incluso, como Estado empresario, pero en un contexto caracterizado por: la inestabilidad institucional que debilita la gestión y continuidad de las políticas públicas; la baja inversión local en investigación y desarrollo del sector privado; la presencia dominante de empresas trasnacionales en los sectores dinámicos, que aplican estrategias desconectadas de los ecosistemas económicos locales; la financiarización especulativa creciente, desde fines de la década de 1970; y la desventaja geopolítica para negociar "reglas de juego" que hagan posible la construcción de capacidades organizacionales, regulatorias, tecnológicas, etc. (Hurtado y Loizou, 2018). No obstante estas limitaciones, es característico de los países de la semiperiferia abordar senderos económicos de aprendizaje y escalamiento tecnológico en industrias dinámicas y retornos crecientes, que no se consideran, para la perspectiva neoclásica dominante en el mainstream, acordes al enfoque de las ventajas comparativas. La respuesta de las economías centrales a este tipo de iniciativas suele ir desde las presiones diplomáticas formales e informales y la competencia desleal hasta las regulaciones obstaculizadoras (Nguyen 2010:244-255; Michalopoulos 2014).

El desarrollo de tecnología espacial en la Argentina, como ejemplo de presiones geopolíticas, pone de manifiesto que el concepto de soberanía no está solamente anclado al territorio y sus fronteras. En efecto, la soberanía no es inherentemente territorial, ni organizada sólo estatalmente. Existen ciudadanos con más de una nacionalidad, circulación de mercancías, acumulación de capital por fuera del Estado de bandera, o problemas transfronterizos ecológicos. También, la información que se transmite por satélite e internet circula a través de las fronteras nacionales (Agnew, 2005b). Los propios satélites geoestacionarios, por ejemplo, poseen posiciones orbitales, ubicadas a 36.000 kilómetros de la superficie terrestre, que son consideradas por los Estados que las coordinan como extensiones de sus soberanías territoriales en el espacio exterior. ${ }^{5}$ No obstante ello, es el Estado (y no el mercado) el que históricamente ha generado en las economías centrales las condiciones para las inversiones pacientes, a riesgo y de largo plazo para el desarrollo de este tipo de tecnologías (Mazzucato, 2013).

En el caso especial de los satélites, concebidos como componentes de la infraestructura global de telecomunicaciones, según Warf (2007:385), "si bien circulan en el espacio, su origen e impacto es sobre la Tierra". Por otra parte, los servicios satelitales, en comparación con la fibra óptica, son más rentables en áreas rurales, remotas, o poco pobladas
5. Las posiciones orbitales son asignadas a los Estados para su coordinación por la Unión Internacional de Telecomunicaciones, organismo dependiente de Naciones Unidas. 
por su capacidad para integrar grandes extensiones territoriales a través de servicios de información. Conjuntamente, como las órbitas a asignar son limitadas, la asignación, regulada por la Unión Internacional de Telecomunicaciones (UIT), presenta muy altos estándares de exigencia. Al presente, estas posiciones están abarrotadas, son muy demandadas (The Independent, 2017), el proveedor principal de servicios satelitales geoestacionarios es EEUU y, por esta razón, el organismo regulatorio internacional "se ve confrontando un dilema entre los Estados ya ocupantes de las órbitas y los nuevos ingresantes que argumentan que aquellos que ya estaban antes se favorecen con una ventaja injusta" (Warf, 2007:388).

\section{NahuelSat y el "negocio" de las comunicaciones satelitales}

Desde comienzos de la década de 1960 la Argentina tuvo un desarrollo incremental de capacidades de cohetes sonda y, desde la década siguiente, también de lanzadores. El Proyecto Cóndor II (1979-1992) representó el punto de mayor desarrollo y, a su vez, de clausura de más de tres décadas de acumulación de capacidades. Enfocado en el desarrollo de un vector balístico, el Proyecto Cóndor II fue iniciado por la Fuerza Aérea Argentina (FFA) luego de la derrota frente al Reino Unido en la Guerra de Malvinas, en 1982. Habiendo perdido gran parte de su material bélico y pilotos, la FFA buscó desarrollar capacidades disuasivas contra la potencia colonial ocupante del territorio en disputa. Llegado el gobierno democrático de Raúl Alfonsín (1983-1989), se procuró continuar con este desarrollo de tecnología dual, aunque las dificultades económicas que atravesaba el país llevaron al proyecto a la virtual asfixia de recursos. Por esta razón, se recurrió al financiamiento externo y a la articulación de una compleja red de empresas europeas, que aportarían el know-how, y de Estados del Medio Oriente, como Egipto o Irak, que aportarían el financiamiento, configuración que desencadenó presiones diplomáticas crecientes -la exigencia de adhesión al Régimen de Control de Tecnología Misilística, la amenaza de sanciones económicas y eventuales restricciones a la transferencia de tecnología, entre otras-, que hicieron eclosión durante el gobierno de Carlos Menem (19891999). Las presiones internacionales, el ahogo presupuestario, y un viraje de la política exterior argentina decidieron la cancelación y desmantelamiento del proyecto en 1991.

En paralelo al proceso de cancelación del Proyecto Cóndor II se crea, en 1991, la Comisión Nacional de Actividades Espaciales (CONAE), con el objetivo de desplazar el sector espacial a la esfera civil, enmarcar la política espacial en la política exterior y reorientarla hacia las misiones satelitales y el desarrollo de satélites de observación nacionales. Estas iniciativas deben comprenderse en un contexto de subordinación a la política exterior de EEUU, que presenta como contraparte económica la profundización del régimen de acumulación basado en la valorización financiera, iniciado en Argentina durante la última dictadura (1976-1983). Esta modalidad de neoliberalismo subordinado con características específicas de la semiperiferia se canaliza a través de la desregulación de flujos financieros y comerciales; el desmantelamiento de las políticas tecnológicas e industriales; y la privatización de los sectores económicamente estratégicos en paralelo a la promoción de la inversión extranjera directa. Las consecuencias más visibles de este escenario son el impacto negativo sobre procesos de aprendizaje y escalamiento tecnológico y organizacional en manos del Estado, la destrucción de capacidades estatales de regulación, coordinación y gestión de políticas, y la primarización y extranjerización de la economía. ${ }^{6}$ La subordinación geopolítica y geoeconómica también supone el abandono de la idea del desarrollo autónomo de tecnologías (Blinder, 2015b y 2017a; Hurtado y Souza, 2018).

De manera absolutamente desconectada de la política espacial, desde comienzos de la década de 1990, el gobierno de Menem decide impulsar "el negocio" de las 
comunicaciones satelitales. Luego de algunos pasos iniciarles, en 1995, la Secretaría de Comunicaciones impulsó la conformar la primera empresa de comunicaciones satelitales con base en Argentina. ${ }^{7}$ La participación accionaria quedó compuesta por Daimler-Benz Aerospace (11\%), Aerospatiale (10\%), Alenia Spazio (10\%), Richefore Satellite Holding Ltd (Jersey, Chanell Island, 17.5\%), Lampebank International (Luxembourg, 11.5\%), International Finance Corporation (IFC del World Bank Group, 5\%), Banco de la Provincia Group (Argentina, 11.5\%), BISA/Bemberg Group (Argentina, 11.5\%), ANTEL (Uruguay, 6.5\%) y Publicom SA (Argentina, 5.75\%) (Oyarzábal, 1997: 17).

NahuelSat obtuvo del Estado argentino una licencia por 24 años, con posibilidad de extensión por seis años, para operar el "Sistema de Satélite Nacional Multipropósito". También se le transfirió la gestión de la posición orbital geoestacionaria de $71.8^{\circ}$ de longitud oeste $\left(71.8^{\circ} \mathrm{O}\right)$ asignada a la Argentina por la UIT. En 1996, NahuelSat inauguró la Estación Terrena de Benavídez y, el 30 de enero de 1997, fue lanzado el Nahuel-1 desde Kourou (Guyana Francesa) con un cohete Ariane 44L el Nahuel-1 para ocupar la posición argentina. El 6 de febrero, el Nahuel 1 desplegó con éxito sus paneles solares y entró en servicio a fines de abril. Por un requerimiento de las compañías de seguros, fue construido un gemelo de ese satélite, que podría en el futuro ocupar la posición orbital adicional que la Argentina esperaba obtener de la UIT.

En 1998, los gobiernos de Argentina y EEUU firmaron un acuerdo de reciprocidad que fue motivado por la presión de la empresa multinacional estadounidense DirecTV, filial de Hughes Electronics, para entrar al mercado argentino y poder transmitir el Mundial de Fútbol a jugarse en Francia. El concepto de "reciprocidad" implícito en la negociación era muy desfavorable para la empresa NahuelSat, que enfrentaba el aumento de competencia en el mercado local sin la posibilidad real de prestar servicios en el mercado norteamericano. NahuelSat se quejó al gobierno argentino, presionando para que se reabriera la negociación. El resultado fue la cesión de EEUU de la posición orbital ubicada en $81^{\circ} \mathrm{O}$, para que Argentina obtuviera la coordinación de la UIT. La segunda posición fue cedida por GE Americom, que más tarde pasaría a ser transitoriamente accionista mayoritario de NahuelSat (Clarín, 1997).

Obstaculizada por sucesivas modificaciones de la composición accionaria de NahuelSat, donde se enfrentaron los intereses de los grandes grupos empresariales de Europa y EEUU, la empresa de capitales extranjeros con base en Argentina NahuelSat incumplió sistemáticamente con el compromiso de ocupar la órbita $81^{\circ} \mathrm{O}$. Frente al riesgo de que la UIT decidiera quitarle esta posición a la Argentina, el Reino Unido hizo reiterados reclamos formales de esta posición orbital.

Durante el gobierno de Fernando De la Rúa (1999-2001), la aprobación del "Reglamento de Gestión y Servicios Satelitales", que hizo posible que la firma de una serie de acuerdos de reciprocidad quedara en manos de la Secretaría de Comunicaciones, se torna más frágil la posición de NahuelSat. En el período 2000-2001, la administración De la Rúa impulsó la firma de acuerdos de reciprocidad con Canadá, México, España, Brasil y Holanda, y autorizó la entrada al mercado local de por lo menos 18 satélites. La crisis terminal de 2001 consolidó la tendencia al inviabilidad de NahuelSat. Todo ello en un contexto de crisis económica generalizada, que terminaría con la renuncia del presidente.

El gobierno de transición de Eduardo Duhalde (2002-2003) se propuso "un cambio de modelo económico" que se centraría en los sectores productivos como eje de la recuperación, en lugar de las finanzas, el endeudamiento y las empresas privatizadas (Zícari, 2017:37). Finalmente, en mayo de 2003 fue electo presidente Néstor
7. En lo que sigue, la trayectoria de NahuelSat se basa en Hurtado y Loizou (2018). 
Kirchner (2003-2007). El nuevo gobierno se propuso abandonar un cuarto de siglo de políticas neoliberales subordinadas e iniciar un proceso de recuperación de las capacidades del Estado para impulsar un nuevo ciclo de industrialización (Manzanelli y Basualdo, 2017). En 2004, anunció el plan de conformación de la Empresa Argentina de Soluciones Satelitales (ARSAT). El Poder Ejecutivo elevó al Congreso de la Nación una propuesta de ley para crear una sociedad anónima con participación estatal -que terminó siendo 100\% pública- con la misión de: proteger las dos posiciones orbitales que la UIT asignara a nuestro país; inaugurar un sendero de producción nacional de satélites geoestacionarios, lo que significaría el despliegue de una política tecnológica con proyecciones hacia la generación de un nuevo sector de alto valor agregado; y desarrollar los servicios satelitales a partir de una posición estratégica del Estado. Como contraparte, el Estado argentino se hacía cargo del riesgo que suponía la inversión necesaria para el desarrollo y fabricación local de los satélites, además de asegurar la soberanía a través de la ocupación de las posiciones orbitales, que pasaban a ser concebidas como extensión de la soberanía territorial al espacio exterior.

En paralelo, frente a la falta de definiciones de NahuelSat, en abril de 2004, el nuevo secretario de Comunicaciones Guillermo Moreno, comenzó a exigirle a NahuelSat la búsqueda de socios para lograr inversiones de, por lo menos, el 50\% de los 300 millones de dólares necesarios para la construcción y el lanzamiento del segundo satélite. Una posibilidad considerada fue abrir a la Bolsa una parte del capital de NahuelSat, que en ese momento estaba constituida por el consorcio europeo EADS -poco más tarde Airbus Group- (47,33\%), SES Global $(28,75 \%)$ y la empresa italiana Finmeccanica $(11,67 \%)$ como accionistas mayoritarios. ${ }^{8}$ La empresa había logrado reestructurar una deuda de 70 millones de dólares, mayormente con bancos europeos y poco menos del $20 \%$ con la International Finance Corporation, organización asociada al Banco Mundial. Una segunda posibilidad era la apertura del capital del satélite Nahuel 2 para que funcionara como una nueva sociedad. Finalmente, también se hablaba de emitir obligaciones negociables. El gobierno y NahuelSat habían logrado una prórroga para ocupar la posición orbital de $81^{\circ} \mathrm{O}$ hasta octubre de 2005. También se hablaba de contratar provisoriamente un satélite sustituto (Infobae, 2004; Cronista Comercial, 2006b). Sin embargo, a mediados de agosto de 2004, frente a la falta de señales claras de la empresa, el gobierno decidió revocar, "por razones de ilegitimidad", la concesión de la coordinación de la posición de $81^{\circ} \mathrm{O}$ y de las bandas de frecuencias asociadas otorgada a NahuelSat (Resolución 188 del 17 de agosto 2004 de la Secretaría de Comunicaciones).

A comienzos de abril de 2006, la Cámara de Diputados sancionó finalmente la ley 26.092 por la cual se creaba la empresa ARSAT y se le otorga el uso de la posición orbital de $81^{\circ} \mathrm{O}$ y de las frecuencias asociadas y a fines de mayo el gobierno oficializó la creación de ARSAT. ${ }^{9}$ Si bien, en paralelo, NahuelSat intentaba recomponer su situación frente al gobierno nacional, a fines de octubre, Moreno negociaba con los accionistas de NahuelSat el pase de los activos de esta empresa a ARSAT sin ningún costo. La idea era que no se transfieran al Estado los pasivos, estimados en 32 millones de dólares a comienzos de 2006. En ese momento la composición accionaria de NahuelSat era un $66,66 \%$ propiedad del consorcio EADS y un $33,33 \%$ de la italiana Finmeccanica (El Cronista, 2006b).

En octubre se aceleró el proceso de integración de transferencias de los activos de NahuelSat a ARSAT. Finalmente, se firmaron dos cartas de intención entre las dos empresas. A través de la primera, NahuelSat le transfería a ARSAT el Nahuel 1, la estación terrestre y la posición orbital de $71.8^{\circ} \mathrm{O}$. A través de la segunda carta dejaba en manos de ARSAT las acciones de NahuelSat por el valor simbólico de un peso. El Estado se hacía cargo de las contingencias (Naishtat, 2006; El Cronista, 2006b).
8. En noviembre de 1998 , se habían fusionado Daimler-Benz Aerospace y Chrysler Corporation para formar DaimlerChrysler Aerospace y, en julio de 2000 , este grupo a su vez se fusionó con AérospatialeMatra de Francia y Construcciones Aeronáuticas de España para crear la European Aeronautic Defence and Space Company (EADS). Por su parte, en 2001, the Societé Européenne des Satellites - una firma con sede en Luxemburgo- pasó a llamarse SES Global. Hoy esta firma es el mayor operador en el mundo de las comunicaciones satelitales y un pionero tecnológico.

9. La iniciativa había sido aprobada por el Senado a fines de septiembre de 2005 con disidencias de la Unión Cívica Radical y del socialismo. Ahora que completaba la aprobación en el Parlamento, el Interbloque Propuesta Federal, liderado por Mauricio Macri, y el ARI, liderado por Elisa Carrió, cuestionaban que la mayor parte de la nueva empresa quedara en manos privadas por medio de la distribución del paquete accionario, así como el contro sobre las posiciones orbitales. 


\section{ARSAT y las comunicaciones satelitales como sector estratégico}

Cambiando la filosofía y la orientación de lo que se había hecho hasta ese momento en política de comunicaciones satelitales, ARSAT se proponía "realizar por sí, o por cuenta de terceros o asociada a terceros el diseño, el desarrollo, la construcción en el país, el lanzamiento y/o la puesta en servicio de satélites geoestacionarios de telecomunicaciones" en las posiciones orbitales que la UIT le asignara a la Argentina, además de las bandas de frecuencias asociadas, según el texto del decreto $\mathrm{N}^{\circ} 634$ por el cual el PEN ordenaba la protocolización del acta de constitución y conformación de los estatutos societarios de la nueva empresa (Decreto 634 del 22 de mayo de 2006).

Así, la nueva empresa iba a ser la encargada de construir, lanzar y operar el satélite ARSAT 1 con un costo estimado de 250 millones de dólares. El gobierno le propuso a la empresa INVAP el diseño y fabricación del satélite, que debería estar listo entre 2007 y 2009. También se comenzó a explorar la posibilidad de que los satélites sean puestos en órbita desde China y que empresas de este país también fueran proveedoras de INVAP, aunque más tarde se abandonaría esta opción. El principal activo de ARSAT era la posición orbital de $81^{\circ} \mathrm{O}$. Cuando el satélite estuviera funcionando a régimen, se estimaba que la explotación de esa posición representaría una facturación anual de 90 millones de dólares (Cronista Comercial, 2004a, 2004b, 2005a y 2006c).

El primer satélite demandaría cuatro años (Cronista Comercial, 2005b). Ahora bien, mientras se avanzaba en estos planes, la preservación de la posición $81^{\circ} \mathrm{O}$ fue una tarea ardua. Hagamos un paréntesis para comprender este punto. La posición $81^{\circ} \mathrm{O}$ había sido necesario ocuparla antes del 19 de octubre de 2005. Con este fin se había alquilado a Venezuela el satélite Anik E2, de la empresa Telesat, por 2,1 millones de dólares. Era un satélite que había sido puesto en órbita en 1991, que ocupaba la posición de $67^{\circ}$ O y que una tormenta solar había averiado en enero de 1994 (Lam et al., 2012). Este satélite llegó a ocupar la posición en el límite de la prórroga otorgada por la UIT, pero al llegar a la posición de $81^{\circ} \mathrm{O}$ su combustible se agotó en 20 días y dejó de operar el 23 de noviembre de 2005 .

En medio de estas contingencias, el gobierno argentino había logrado finalmente demorar la decisión sobre esta posición orbital, no a través de una prórroga formal, sino a través de una prórroga de hecho, dado que la UIT decidió que se iba a expedir de manera definitiva en la Conferencia Mundial que el organismo iba a realizar en 2007. En febrero de 2006, el Reino Unido pidió a la UIT que se le quitara a la Argentina la coordinación de la posición de $81^{\circ} \mathrm{O}$ alegando que el satélite Anik E2 había sufrido problemas técnicos serios. La UIT rechazó el reclamo británico (Convergencia Latina, 2005; Cronista Comercial, 2006a).

Como vimos, en abril de 2006 se crea ARSAT y, pocos meses más tarde, se clausura NahuelSat. Por acuerdo con IntelSat, firmado el 20 de marzo de 2007, se contrató el satélite G-17 -o Galaxy-17-, que fue puesto en órbita y comenzó a transmitir desde la posición de $81^{\circ} \mathrm{O}$ a mediados de mayo. Este acuerdo suponía que, si Intelsat tuviera cualquier inconveniente con el G-17, entonces colocaría en la posición de $81^{\circ} \mathrm{O}$ el satélite SBS-6. El 9 de mayo, IntelSat y ARSAT acordaron la migración del G-9 desde la posición de $74^{\circ} \mathrm{O}$ a la posición $81^{\circ} \mathrm{O}$ por el término de un año desde comienzos de octubre, cuando se concretó el posicionamiento. En diciembre se prorrogó por un año adicional el acuerdo con IntelSat. A comienzos de diciembre de 2008, con Cristina Fernández como presidenta (2007-2015), se firmó un nuevo acuerdo de colaboración con IntelSat para llevar el SBS-6 a la posición $81^{\circ}$ O. Finalmente, el 30 de marzo de 2010 se firmó otro acuerdo con IntelSat para ubicar temporalmente el IS-3R en la posición $81^{\circ} \mathrm{O}$, que se hizo efectiva el 19 de noviembre de 2010. A mediados de julio de 2010, el Nahuel 1 ocupó la posición $81^{\circ} \mathrm{O}$ (AGN, 2012:12-21). A esta altura, ya es claro que 
esta posición orbital representa un claro ejemplo de los costos de transacción anómalos que debe afrontar un país semiperiférico si quiere acceder a sectores reservados para las economías avanzadas.

Retomando los inicios de ARSAT, mientras se avanzaba en la contratación del diseño y construcción del primer satélite geoestacionario, puede dar una idea de los intereses geopolíticos en juego en el campo satelital un cable que a fines de junio enviaba a varios organismos de su gobierno la Embajada de EEUU en Buenos Aires con información considerada "sensitiva". El texto daba los fundamentos de su apoyo a un préstamo del Banco Interamericano de Desarrollo (BID) por 50 millones de dólares a la CONAE para la construcción y lanzamiento de un satélite de teledetección en la banda L de radar, el SAC-D. El informe se oponía a algunas objeciones de otros actores del gobierno de EEUU que sostenían que se trataba de un "classic trophy project", que los satélites no eran una política prioritaria para la Argentina y que "el BID debería enfocarse en el alivio de la pobreza y el cambio de régimen político" (Embajada de EEUU, 2006).

La embajada en Buenos Aires apoyaba la concesión del crédito por considerarlo de interés nacional para EEUU: "Este préstamo ayudaría a desarrollar una de las pocas áreas tecnológicas donde Argentina es globalmente competitiva y también una en la cual el gobierno de EEUU y las empresas norteamericanas estaban trabajando en cooperación con Argentina". El mismo documento agregaba: "El ejército de EEUU tiene intereses directos en la tecnología que resultaría de este proyecto en el futuro". Si bien había algunas reservas respecto al pedido de excepción de las reglas de contratación del BID, "esto puede tener menos relevancia en el contexto argentino, donde existe una sola empresa que puede hacer este tipo de trabajo, una que abastece el 90 por ciento de sus adquisiciones de EEUU”. Esta empresa era INVAP, que sería casi seguramente la ganadora del contrato y cuya línea de suministros era "muy dependiente de la tecnología de EEUU, lo que no solo significa que las empresas de EEUU recibirán una gran parte de los recursos del préstamo, sino también que se aplicarán las restricciones tecnológicas de EEUU" (Embajada de EEUU, 2006).

Es decir, mientras que el préstamo sería para la CONAE, esta agencia lo utilizaría para contratar empresas. Lo novedoso era que Argentina produciría el satélite, lo que se ajustaba a los objetivos de "aumentar la competitividad nacional" y "reconstruir el capital humano", que establecía el BID para Argentina. También se comentaba en este documento que "las capacidades en tecnología satelital de Argentina no llegaban a la construcción de satélites de telecomunicaciones", según los contactos con el sector privado de EEUU, que informaban a la Embajada que "INVAP no tiene todavía la capacidad técnica necesaria para competir a nivel mundial". Finalmente, el US Army International Technology Center South America (USAITC-SA) estaba instalado en Argentina "para identificar la tecnología argentina que podría ser útil para EEUU en aplicaciones en defensa, incluyendo a INVAP [...]. Dos entidades militares de EEUU están interesadas en la tecnología satelital de INVAP para Sistemas de Combate Futuros" (Embajada de EEUU, 2006).

El costo total de fabricación y puesta en órbita del satélite que estaba a cargo de INVAP se estimaba en ese momento en 150 millones de dólares y su desarrollo -planos y plan de producción- alrededor de 30 millones. Quedaba pendiente el acuerdo que el Estado había firmado con Telesat para que, a cambio del compromiso de la empresa canadiense de ocupar la posición de $81^{\circ} \mathrm{O}$ a un costo de 2 millones de dólares, el Estado le vendiera capacidad en la posición $81^{\circ} \mathrm{O}$ a precios subsidiados (CanalAR, 2006; Convergencia Latina, 2006; Cronista Comercial, 2006e).

En este punto, es importante recordar que a la quiebra de Lehman Brothers, a mediados de septiembre de 2008, que desencadena un colapso financiero global, se suman en el orden interno las tensiones crecientes entre el gobierno y los grandes grupos 
agroexportadores - a partir del conflicto por "la 125 "-,,${ }^{10}$ alineados con sectores financieros -los "fondos buitres" incluidos-, que se manifestaron a través de "fuertes maniobras especulativas en procura tanto de ganancias fáciles como de desestabilizar al gobierno" (Porta et al., 2017:126) y de ataques a través de la prensa, inéditos por su virulencia, de estas mismas fracciones económicas concentradas que dominaban los medios de comunicación.

En este contexto de crecientes confrontaciones, a partir de 2010, los procesos de toma de decisiones comenzaron a acelerarse, los objetivos de ARSAT se fueron diversificando y las políticas de telecomunicaciones fueron ganando una dimensión sistémica. Entre otras iniciativas, se inicia la construcción de la primera red troncal de fibra óptica estatal de Sudamérica, un proyecto que se propone la construcción de más de 35.000 kilómetros de conexiones federales con el propósito de cambiar el paradigma de las comunicaciones en nuestro país. También se inicia ese año la construcción de la plataforma de distribución de la Televisión Digital Abierta, gratuita y de alta calidad. Todas estas acciones están orientadas a la satisfacción de los desafíos técnicos que exigía la hoy trunca ley de "Servicios Comunicación Audiovisual". ${ }^{11}$ En ese momento, en la sala limpia de la empresa INVAP se podían ver, en simultáneo, tres satélites en proceso de construcción: el SAC-D, el SAOCOM-1A y el ARSAT-1 (Hurtado et al., 2017: 63-64). En junio de 2011 fue lanzó exitosamente la misión SAC-D/Aquarius desde la Base Vandenberg (California). Se trataba de una misión impulsada por la CONAE en sociedad con la NASA, que suministró el instrumento Aquarius. El objetivo principal de esta misión era medir la salinidad superficial de los mares y océanos para modelos de cambio climático (Drewes, 2014:16-17).

A comienzos de enero de 2012, la asamblea de accionistas de ARSAT aprobó la designación de Guillermo Rus, ingeniero en sistemas, como vicepresidente en reemplazo de Fabio Fabiani, que había renunciado a fines de diciembre para trabajar junto al gobernador de Jujuy. ${ }^{12}$ El grupo oligopólico Clarín aprovechó estos cambios para amplificar sus operaciones de desprestigio del gobierno. En una nota sin firma, titulada "La Cámpora ya pisa terreno de Julio De Vido", se buscaba sobredimensionar supuestos enfrentamientos entre el ministro de Economía, Axel Kicillof, miembro de la organización La Cámpora, y el ministro de Planificación a partir del hecho de que el nuevo vicepresidente de ARSAT también pertenecía a esta agrupación política (Clarín, 2012).

En septiembre, el gobierno anunció que cancelaba la licitación en curso de una parte del espectro radioeléctrico para telefonía móvil para asignarlo ARSAT. A más de 20 años de la privatización de la Empresa Nacional de Telecomunicaciones (ENTel), la cancelación del concurso en marcha y la decisión del gobierno de asignar el espectro disponible a ARSAT comenzaba a poner en evidencia la intención de orientar la empresa estatal hacia la prestación integral de servicios de telecomunicaciones, esto es, transmisión satelital, banda ancha, fibra óptica, telefonía móvil y televisión digital terrestre, además de la promoción de una industria satelital nacional (Fontanals, 2014: 24).

La empresa estatal administraba el espectro que había recibido en 2008 del grupo Telefónica tras la fusión en 2005 de su operadora Unifón con Movicom (BellSouth) para formar Movistar, porque superaba los 50 megahertz de ancho de banda que era permitido a cada operador y ocupaba el $22 \%$ del total del mercado. ${ }^{13}$ El gobierno se había comprometido a licitarlo, pero evitando las posiciones dominantes. Finalmente, en la última licitación las empresas que presentaron ofertas fueron declaradas no aptas y el gobierno anunció la anulación de la convocatoria y el otorgamiento de las frecuencias al Estado. Así, ARSAT se quedaba con las frecuencias disponibles en las bandas de 850 y 1900 megahertz, en pie de igualdad con Claro, Movistar y Personal. Se hablaba de que se podría licitar parte de esta capacidad y parte se emplearía para Televisión Digital Abierta (TDA) (Telam, 2012; Fuks, 2013).
10. Sobre el conflicto desencadenado por la Resolución 125 del Ministerio de Economía, ver: Kulfas (2016:128-134).

11. La ley 26.522, promulgada el 10 de octubre de 2009, reemplazó la "Ley de Radiodifusión" de la última dictadura. Sin embargo, el Grupo Clarín, a través de sucesivas medidas cautelares, logró paraliza la aplicación plena de la ley hasta que, a fines de octubre de 2013, la Corte Suprema de Justicia determinó la validez de los cuatro artículos cuestionados por el Grupo Clarín y la constitucionalidad general de la ley. Sin embargo, a pesar del amplio consenso alcanzado, a comienzos de 2016, la ley fue modificada por Mauricio Macri a través de un decreto de necesidad y urgencia. 12. En ese momento, el directorio de ARSAT estaba integrado por: Pablo Tognetti (presidente); Fabio Fabiani (vicepresidente renunciante); Rodolfo Koennecke (director); Miguel Ángel Pesado (director); Marcelo Tesoro (director).

13. El resto del espectro se distribuía entre Telefónica (29\%), Personal-Telecom (27\%) y Claro de Telmex (23\%). Habían entrado en la competencia Claro, Multitrunk del grupo Roggio, Nextel, Personal, Viettel y Superphone del grupo Vila-Manzano. 
Con la presencia de Cristina Fernández, a fines de septiembre de 2013, se inauguró en Bariloche la empresa CEATSA (Centro de Ensayos de Alta Tecnología), una sociedad entre INVAP y ARSAT, que contaba con las instalaciones necesarias para hacer los ensayos ambientales para la industria satelital y en la que se invirtieron 40 millones de dólares. Como consecuencia del programa satelital, el plan de radarización de los aeropuertos argentinos y la exportación de tecnología nuclear, entre otros proyectos, desde 2003 hasta la fecha el personal de INVAP pasó de 350 a 1100 personas y su facturación de 30 a 200 millones de dólares anuales (Krakowiak, 2013).

Finalizada la auditoría y revisión de procedimientos, el manejo del riesgo y control de calidad, ARSAT y Nación Seguros, respaldadas por reaseguradoras internacionales, firmaron en 2014 la póliza de los satélites ARSAT-1 y 2. El 16 de octubre de 2014, fue lanzado el ARSAT-1 en el cohete Ariane 5 desde la base de Kourou, en Guyana Francesa. Desde la Estación Terrena Benavídez se colocó al satélite en la órbita $71.8^{\circ}$ $\mathrm{O}$, a 35.786 kilómetros de altura. El 30 de septiembre del año siguiente fue lanzado el ARSAT 2 y ubicado en la posición orbital $81^{\circ}$ O. En 2015, ARSAT era una empresa en expansión que contaba con dos satélites geoestacionarios diseñados y construidos localmente, y que ocupaban las dos posiciones orbitales nacionales, un Centro de Datos de 4500 metros cuadrados con certificación internacional Tier III y personal calificado, 88 estaciones terrestres de Televisión Digital Abierta (TDA) en su última etapa de despliegue, que había logrado cubrir el $80 \%$ de la población con el servicio terrestre y el 100\% del territorio con el servicio satelital -incluyendo la Península Antártica y las Islas Malvinas-, en proceso de tendido de una red troncal, clientes como los operadores Claro o Telefónica Argentina y un cronograma para finalizar la puesta en operación a fines de 2016 (Rus, 2017).

\section{Tecnología, industria y resignificación del territorio}

Los satélites ARSAT están fabricados con componentes nacionales y extranjeros aproximadamente en proporciones similares. De los componentes nacionales, mayormente el valor agregado proviene de INVAP. Según Guillermo Rus, ex vice presidente de ARSAT, esta empresa se encargó del desarrollo de la computadora de abordo, aunque también participaron empresas como Mecánica 14, especializada en mecánica de precisión con sede en Córdoba, o la empresa de simulación computacional SIM \& TEC, con sede en Buenos Aires. Sin embargo, "la mayor parte se hizo en Bariloche" (Rus, 2018). Las empresas extranjeras que participaron en la fabricación fueron casi todas Europeas: EADS Astrium (Francia), Thales Alenia Space (Francia), RUAG (Suiza), Selex Galileo (Italia), Ariane Space (Francia). Todas tienen su producción distribuida por otros países de ese continente, como Alemania, Bélgica, España, Reino Unido, Suecia, entre otros. ${ }^{14}$ También, participó Honeywell (EEUU).

Mientras que ARSAT 1 costó 350 millones de dólares, el costo de ARSAT 2 fue 250 millones de dólares. La diferencia de 100 millones entre ambos satélites se debe a que parte de la infraestructura y el instrumental necesarios para la fabricación del primer satélite luego pudieron ser empleados para el segundo. Alrededor de 100 millones se invirtieron en el lanzamiento del satélite, 50 millones en la integración del satélite, que es trabajo de INVAP, 50 millones en la carga útil, y 50 millones en componentes, algunos importados. Si se excluye el lanzamiento, INVAP aporta el 50\% del valor del satélite (Rus, 2018). De las limitaciones con respecto a las capacidades nacionales de fabricación de componentes tecnológicos se infieren, como veremos abajo, condicionamientos de orden geopolítico, en este caso entrelazados con el lanzamiento, en manos de una empresa europea que se concreta desde otro país.
14. Resulta difícil acceder a la información de la exacta locación de la fabricación de cada uno de los componentes adquiridos en estas empresas, debido a la complejidad de los sistemas integrados, y la propia dinámica reservada de la información sobre la trama de trabajo que estos consorcios producen. 
Los satélites ARSAT 1 y 2 se fabricaron y testearon en las instalaciones de INVAP y CEATSA, en Bariloche, y luego fueron transportados por un avión de carga Antónov AN-124 al Centre Spatial Guyanais, el puerto espacial francés en Kourou, Guyana Francesa, territorio colonial en América del Sur. De allí partieron ambos satélites verticalmente hasta sus posiciones orbitales geoestacionarias. ¿Por qué se utilizó para el transporte un Antonov ruso y no otro avión de carga? Fue una solución de logística, una decisión en base a una estimación costo-beneficio para el servicio de traslado ¿Por qué no se eligió otro sistema de lanzamiento en otro país? Porque se buscó cumplir con los marcos normativos impuestos por las Traffic in Arms Regulations (ITAR). Estas normas imponen limitaciones que entrelazan los intereses comerciales y geopolíticos de los países centrales. Por ejemplo, las ITAR imponen que si los satélites incluyen componentes estadounidenses, entonces no puede utilizar lanzadores chinos. A la propia CONAE y al Plan Espacial argentino le impuso algunas limitaciones. "Con respecto a las sociedades de nuestra agencia espacial, los lanzamientos de la serie SAC se han hecho con la NASA". En esta dirección, Rus explica que "el lanzador de China ya estaba vedado a partir del régimen de ITAR". Estas son las limitaciones que deben enfrentarse cuando no se dispone la capacidad de producir en el país determinados componentes (Rus, 2018). ${ }^{15}$

Para el lanzamiento, Rus explica que se evaluó la posibilidad de utilizar los cohetes lanzadores de United Launch Alliance (ULA) -empresa estadounidense de Lockheed Martin Space Systems y Boeing Defense, Space \& Security-, Sea Launch -empresa de capitales de EEUU, Rusia, Ucrania, y Noruega-, la norteamericana Space X, y la francesa Arianespace. La decisión final dependió de la red de relaciones de los ingenieros y técnicos de ARSAT, cuyas actividades de capacitación y formación tuvieron lugar mayormente en Europa. "La idea era la confiabilidad [...] minimizar los riesgos" (Rus, 2018). Así, la selección obedeció a la confianza de la empresa proveedora del lanzamiento. "ULA era demasiado cara, Space X todavía era poco confiable para el lanzamiento, Sea Launch tuvo algunos problemas [...] y quedó Arianespace que está dentro de la lógica europea de ARSAT" (Rus, 2018). El lanzamiento fue desde Guyana simplemente porque allí se encuentra la plataforma de lanzamiento de Arianespace.

El éxito de la trayectoria inicial de ARSAT motivó que, el 4 de noviembre de 2015, el Congreso Nacional sancionara la ley 27.208 de "Desarrollo de la Industria Satelital", que declaró "de interés nacional el desarrollo de la industria satelital como política de Estado y de prioridad nacional, en lo que respecta a satélites geoestacionarios de telecomunicaciones" y aprobó el Plan Satelital Geoestacionario Argentino 2015-2035 que prevé, entre otros objetivos, el desarrollo nacional de ocho satélites en los siguientes 20 años. ${ }^{16}$

En muchos sentidos, los satélites ARSAT 1 y 2 iniciaron un proceso de resignificación del territorio argentino, de sus representaciones y los imaginarios asociados a las nociones de espacialidad, extensión y soberanía. Por un lado, se puede decir que la trama organizacional que supone fabricar satélites aporta un caso exitoso sobre cómo aumentar la complejidad y densidad de una industria nacional caracterizada por la desarticulación de su aparato productivo. El desarrollo económico se puede medir por la complejidad de los productos que un país produce y logra exportar -que se corresponde de manera proporcional a la complejidad de sus capacidades organizacionales- y los satélites geoestacionarios integran la lista de los 100 productos más complejos a escala global. ${ }^{17}$

Una vez en órbita los satélites, mientras el plan -avalado por una ley- era continúa con la producción de ARSAT 3, ARSAT 4, etc. (al menos esto suponía el plan original plasmado en la ley $\mathrm{N}^{\circ}$ 27.208), los servicios de la empresa ARSAT deberían avanzar en
15. El objetivo del desarrollo del lanzador satelital Tronador supone disponer de capacidad propia, por lo menos para satélites livianos, categoría que no incluye a los geoestacionarios (Blinder, 2014: 308).

16. Un análisis y contextualización de la ley 27.208, puede verse: Bianchi y Rus (2016).

17. Sobre complejidad y desarrollo económico, puede verse: Abdon et al. (2010). 
la equidad digital territorial y en la prestación de servicios a las economías regionales y a su integración. Dos casos paradigmáticos son la autonomía de servicios que estos satélites pueden prestar a las bases argentinas en la Antártida o su pisada sobre las islas Malvinas, dos porciones del territorio sujetas al reclamo de soberanía. Por otro lado, la propia noción de soberanía asociada a las posiciones orbitales como extensión territorial hacia el espacio exterior supone sumarle una dimensión dinámica a las variables espacialidad, extensión y soberanía: en la medida en que Argentina produzca más satélites puede gestionar ante la UIT nuevas posiciones orbitales y avanzar en la densidad de interconexión autónoma.

\section{Geopolítica popular y soberanía tecnológica}

En un acto en la explanada del Ministerio de Ciencia, Tecnología e Innovación Productiva, en noviembre de 2015, Cristina Fernández pronunció un discurso en el cual remarcó los logros del ciclo político que había comenzado en 2003, que se cerraría semanas más tarde con la asunción de Mauricio Macri como presidente y el inicio de un nuevo ciclo de neoliberalismo subordinado vigente al momento de cierre de este artículo, que paralizó la construcción del ARSAT 3 y retomó una política de desregulación de los servicios satelitales idéntica a la de los años noventa. En su discurso, Cristina Fernández se refería los logros científicos y tecnológicos, colocando en un lugar destacado la trayectoria de ARSAT y sus inicios durante la presidencia de Néstor Kirchner, fallecido en octubre de 2010: “¿Saben dónde está él? Allá arriba con el ARSAT 1 y el ARSAT 2. Él está ahí, como una suerte de barrilete cósmico, como una suerte de alguien que soñó tanto y con tanta fuerza un país diferente, que el corazón no le aguantó los sueños" (Visión 7, 2015).

Podríamos multiplicar este tipo de apelaciones simbólicas a los satélites geoestacionarios en otros órdenes de la actividad política y cultural. En este sentido, si bien hubo muchos otros hitos tecnológicos, también inéditos, durante el ciclo político 2003-2015 -en tecnología nuclear, de radares, de producción pública de medicamentos, entre otros-, ninguno iguala en su impacto cultural a los satélites ARSAT. En este sentido, es interesante el paralelismo con el lugar que terminó ocupando el caza a reacción Pulqui II en el imaginario social. Un año antes a este discurso de Cristina Fernández, el lanzamiento del primero de los satélites geoestacionarios se transmitió por cadena nacional y fue presentado como una gesta. La locutora oficial explicaba que el motivo de la cadena nacional era:

[...] el histórico lanzamiento del satélite ARSAT 1, que convierte a la Argentina en el primer país latinoamericano con capacidad de fabricar satélites y exportarlos. Hoy, 16 de octubre, fecha histórica para la ciencia y la tecnología argentina, con el lanzamiento del primer satélite geoestacionario construido íntegramente en el país, ARSAT 1 que es, justamente, propiedad de todos los argentinos y argentinas (Casa Rosada, 2014).

Luego de la presentación, una cámara enfoca a la presidenta mirando en la televisión el conteo reverso, en francés, y el despegue del cohete francés Ariane. En ese momento, la locutora señalaba que se iniciaba el camino a la "soberanía espacial". En una comunicación con el ministro de Planificación Federal, que se encontraba en Kourou, éste contaba " $[. .$.$] estamos todos muy muy emocionados y realmente no nos vamos a olvidar$ nunca de este día" y se refería a tres hitos tecnológicos, el ARSAT 1 que acababa de ser lanzado, la represa hidroeléctrica Yaciretá y la central nuclear Atucha II, que había sido inaugurada recientemente y que en los próximos meses se esperaba que alcanzara el 100\% de su capacidad (Casa Rosada, 2014). 
En esta cadena nacional, Cristina Fernández aparecía en su escritorio, con una foto a sus espaldas del premio Nobel de Fisiología o Medicina argentino Cesar Milstein y una bandera nacional a su derecha. La presidenta recordó los antecedentes del ARSAT 1, pero destacando que en 2004 el país casi pierde la órbita geoestacionaria, episodio que había puesto en peligro la soberanía espacial y tecnológica, y sostuvo que la creación de ARSAT había sido motivada en buena medida por estos episodios. También habló de las más de 1500 personas que participaron del proyecto, "mano de obra altísimamente calificada que requiere este tipo de emprendimientos" (Casa Rosada, 2014).

En sí mismo, representa un hecho inédito el esfuerzo de un/a presidente/a por hacer comprender cómo un hito tecnológico se vinculaba a variables como la soberanía espacial y tecnológica, a los beneficios que significaba para las empresas nacionales que podrían exportar servicios de telecomunicaciones a toda la región, y a la autoestima nacional -" [...] el inmenso orgullo que siento como argentina"-, y también explicaba que estaba en diseño el ARSAT 3, que "nos va a permitir desarrollar y optimizar toda la fibra óptica que hemos construido en todo el país en estos años" (Casa Rosada, 2014).

En síntesis, en una cadena nacional de poco menos de dieciséis minutos aparecían todos los componentes de una política científico-tecnológica articulados con las variables geopolíticas, económicas y culturales. Episodio notable si se tiene en cuenta que una de las grandes debilidades históricas de los países de la región son sus políticas tecnológicas y falta de articulación con la realidad socioeconómica. "En tiempos que los fondos buitre nos quieren hipotecar el presente, y otros que de adentro nos quieren derogar el futuro, les decimos que los sueños no se derogan, que las alas del ARSAT están desplegadas [...] también de Argentina [...] las alas del progreso" (Casa Rosada, 2014).

\section{Reflexiones finales}

En síntesis, la épica de ARSAT supone satélites argentinos en posiciones orbitales argentinas como plataforma económica en red para que empresas argentinas presten servicios de telecomunicaciones en el país y en la región. La autonomía de esta configuración sistémica de un sector de la economía usualmente reservada a los países centrales -y, por lo tanto, de estructura oligopólica- creó las condiciones de posibilidad, por primera vez en la Argentina, para la asimilación de la política de comunicación satelital a las agendas de equidad e inclusión, y de integración territorial. Así, el impacto cultural de los satélites ARSAT, donde convergen variables como industria, territorio, espacio y soberanía tecnológica, pone en evidencia la emergencia de una geopolítica popular que, a nuestro juicio, representa un rasgo crucial en el intento de una democracia semiperiférica para avanzar a contracorriente del mainstream neoliberal que define el orden geopolítico. Como componente de un "sentido común" en formación que incorpora el factor tecnológico como rasgo de identidad nacional, esta geopolítica popular acompaña el intento de ascender en la jerarquía de los Estados y representa la condición de posibilidad para la emergencia de políticas exteriores capaces de enfrentar las variadas presiones formales e informales que se proponen mantener el orden internacional reacciona.

Entre las primeras medidas de la gestión de gobierno que en la Argentina inició un nuevo ciclo de neoliberalismo subordinado en diciembre de 2015 se cuentan la paralización silenciosa de la fabricación del ARSAT 3, la puesta en manos de la consultora norteamericana McKinsey del nuevo "plan de negocios" de ARSAT y su posterior desmembramiento. La política de comunicación satelital del nuevo gobierno desde el inicio replicó la estrategia de la década de los años noventa al permitir el ingreso masivo de satélites extranjeros. Finalmente, en julio de 2017 se filtró una carta de intención 
donde se intentaba avanzar en secreto en la creación de una sociedad entre ARSAT y la empresa norteamericana Hughes, donde la Argentina cedía la mayoría accionaria a la empresa norteamericana.

$\mathrm{Al}$ margen de las consecuencias y repercusiones de estas iniciativas, que escapan a los intereses de este artículo, a modo de cierre nos interesa correlacionar la trayectoria de las comunicaciones satelitales en la Argentina que se inicia con un nuevo ciclo de neoliberalismo subordinado con un discurso oficial que impulsó una campaña de desprestigio de la empresa ARSAT basada en su supuesta inviabilidad, en paralelo al reinicio de un nuevo ciclo de desindustrialización, financierización y extranjerización de la economía y a la eliminación de la agenda política de las múltiples problemáticas relacionadas con la soberanía territorial y tecnológica. Al momento del cierre de este artículo la clausura de lo que hemos llamado geopolítica popular es terreno de disputa cultural y política. 


\section{Q Bibliografía}

"Abdon, A., Bacate, M., Felipe, J. y Kumar, U. (2010). Product Complexity and Economic Development. Levy Economics Institute Working Paper 616. En: http:// www.levyinstitute.org/pubs/wp_616.pdf. Consultado el 10/12/2017.

» Agnew, J. y Corbridge, S. (1995). Mastering space. Hegemony, territory and international political economy. New York: Routledge.

»Agnew, J. (2005). Geopolítica. Una re-visión de la política mundial. Madrid: Trama.

»Agnew, J. (2005b). Sovereignty Regimes: Territoriality and State Authority in Contemporary World Politics. Annals of the Association of American Geographers, 95 (2), 437-461.

»Azpiazu, D. y Schorr, M. (2010). Hecho en Argentina. Industria y economía, 19762007. Buenos Aires: Siglo Veintiuno Editores.

"Bianchi, M. y Rus, G. (2016). El futuro llegó. Plan satelital geoestacionario argentino, 2015-2035. Buenos Aires: Caband.

"Basualdo, E. (2006). Estudios de historia económica argentina. Buenos Aires: Siglo Veintiuno.

"Blinder, D. (2014). Globalización, geopolítica, y tecnologías sensibles en situación periférica: tecnología misilísticalespacial en la Argentina (1989 -2012). Tesis doctoral, Universidad de Buenos Aires, Facultad de Ciencias Sociales.

» Blinder, D. (2015a). “Argentina space: ready for launch”. Space and Defense Journal, 8 (1), 34-46.

"Blinder, D. (2015b). Hacia una política espacial en la Argentina. Revista Iberoamericana de Ciencia Tecnología y Sociedad (CTS), 10 (29), 65-89.

" Blinder, D. (2017a). Argentina en el espacio: política internacional en relación a la política tecnológica y el desarrollo industrial. Revista de relaciones internacionales, estrategia y seguridad, 12 (1), 159-183.

»Blinder, D. (2017b). Orden Mundial y tecnología. Análisis institucional desde la perspectiva geopolítica en la semiperiferia: la tecnología espacial y de misiles en Argentina y Brasil. Revista Geopolítica(s), 8 (2), 177-202.

»Chang, H. (2007). Understanding the relationship between institutions and economic development - some key theoretical issues, pp. 17-34. En: H-J. Chang (ed.) Institutional Change and Economic Development. Londres: Anthem Press.

»Chang, H. (2008). Bad Samaritans. The Myth of Free Trade and the Secret History of Capitalism. New York: Bloomsbury.

"Dittmer, J. (2013). Captain America and the nationalist superhero. Metaphors, narratives and geopolitics. Philadelphia: Temple University Press.

»Dodds, K. (2007). Geopolitics: a very short introduction. Oxford: Oxford University Press.

»Drewes, L. (coord.) (2014). El sector espacial argentino. Instituciones, empresas y desafíos. Benavídez: ARSAT.

"Eudaily, S. and Smith, S. (2008). Sovereign Geopolitics? - Uncovering the "Sovereignty Paradox". Geopolitics Journal, 3 (2), 309-334. 
»Hurtado, D. (2015). Semi-periphery and capital-intensive advanced technologies: The construction of Argentina as a nuclear proliferation country. Journal of Science Communication, 14 (2), Ao5.

" Hurtado, D., Bianchi, M. y Lawler, D. (2017). Tecnología, políticas de Estado y modelo de país: el caso ARSAT, los satélites geoestacionarios versus 'los cielos abiertos'. Epistemología e Historia de la Ciencia (Universidad Nacional de Córdoba), 2 (1), 48-71.

» Hurtado, D. y Loizou, N. (2018, en prensa). Desregulación de sectores estratégicos en contexto semiperiférico: las comunicaciones satelitales en la Argentina, 1991-2003. América Latina en la Historia Económica.

»Hurtado, D. y Souza, P. (2018). Geoeconomic Uses of Global Warming: The "Green" Technological Revolution and the Role of the Semi-Periphery. Journal of World-System Research, 24 (1), 123-150.

" Kulfas, M. (2016). Los tres kirchnerismos. Una historia económica argentina, 20032015. Buenos Aires: Siglo Veintiuno.

»Manzanelli, P. y Basualdo, E. (2017). La era kirchnerista. El retorno a la economía real, el desendeudamiento externo y las pugnas por la distribución del ingreso, 2003-2015, pp. 75-110. En: E. Basualdo (ed.), Endeudar y fugar. Un análisis de la historia económica argentina, de Martínez de Hoz a Macri. Buenos Aires: Siglo XXI.

» Mazzucato, M. (2013). The entrepreneurial state: debunking public vs. private sector myths. London: Anthem Press.

» Michalopoulos, C. (2014). Emerging Powers in the WTO. Developing Countries and Trade in the 21st Century. New York: Palgrave Macmillan.

" Nguyen, T. T. (2010). Competition Law, Technology Transfer and the TRIPS Agreement. Implications for Developing Countries. Cheltenham, UK: Elgar.

» Oyarzábal, X. (1997), Argentine Space Assets, Ph.D. Thesis, Postgraduate Naval School, Monterrey, California.

"Porta, F., Santarcángelo, J. y Schteingart, D. (2017). Un proyecto político con objetivos económicos. Los límites de la estrategia kirchnerista, pp. 99-143. En: Pucciarelli, A. y Castellani, A. (eds.), Los años del kirchnerismo. La disputa hegemónica tras la crisis del orden neoliberal. Buenos Aires: Siglo Veintiuno.

» Taylor, P. y Flint, C. (2002). Geografía política. Economía-Mundo, Estado-Nación y localidad. Madrid: Trama.

»Wallerstein, I. (2005). El moderno sistema mundial. Tomo I. Méjico: Siglo XXI.

»Warf, B. (2007). Geopolitics of satellite industry. Journal of economic and social geography, 8 (3), 385-397.

"Zícari, J. (2016). Del colapso de la convertibilidad a las bases económicas de la recuperación, pp. 35-6o. En A. Pucciarelli y A. Castellani (eds.), Los años del kirchnerismo. La disputa hegemónica tras la crisis del orden neoliberal. Buenos Aires: Siglo Veintiuno.

\section{Documentos}

» AGN (2003). Informe de auditoría de la Comisión Nacional de Telecomunicaciones. Buenos Aires, Departamento de Control del Sector Comunicaciones, 13 de febrero. Actuación AGN N²68/01. 
》AGN Anexo (2003). Anexo I de la actuación 268/01 del Informe de auditoría de la Comisión Nacional de Telecomunicaciones. Buenos Aires, Departamento de Control del Sector Comunicaciones, 13 de febrero. Actuación AGN N²68/01.

» AGN (2012). Informe de auditoría de la Secretaría de Comunicaciones, la Comisión Nacional de Comunicaciones, ARSAT. Buenos Aires, Departamento de Control del Sector Comunicaciones, 13 de septiembre. Actuación AGN Nº 195/10.

»Arsat (2009). Arsat adjudicó componentes para su satélite ARSAT-1, 8 de septiembre. En: http://www.arsat.com.ar/novedades/arsat-awards-contractsfor-the-construction-arsat-1-satellite-components. Consultado el 15/07/2016. Consultado el 15/07/2016.

" Arsat (2010a). Proyecto Plataforma TV Digital y Directa al Hogar, 20 abril. En: http://www.arsat.com.ar/novedades/april-2010-digital-television-platformand-direct-to-home-television-project. Consultado el 15/07/2016.

»Arsat (2010b). Arsat-1, será lanzado por la empresa francesa Arianespace, 20 de abril. En: http://www.arsat.com.ar/novedades/april-2010-french-arianespaceto-launch-argentine-satellite-arsat-1. Consultado el 15/07/2016.

»Arsat (2012a). Certificación Internacional Tier III para el Data Center, s/f. En: http://www.arsat.com.ar/novedades/certificacion-internacional-tier-iii-para-eldata-center. Consultado el 18/07/2016.

»Arsat (2012b). ARSAT inaugura 13 estaciones digitales terrestres en Venezuela, s/f. En: http://www.arsat.com.ar/novedades/arsat-inaugura-13-estacionesdigitales-terrestres-en-venezuela. Consultado el 23/07/2016.

" Arsat (2014a). Aseguraron al ARSAT-1, primer satélite de telecomunicaciones argentino, s/f. En: http://www.arsat.com.ar/novedades/aseguraron-al-arsat-1primer-satelite-de-telecomunicaciones-argentino. Consultado el 25/07/2016.

»Arsat (2014b). Exitoso lanzamiento del ARSAT-1 al espacio, s/f. En: http://www. arsat.com.ar/wp-content/uploads/2014/10/Exitoso-lanzamiento-del-ARSAT. pdf. Consultado el 18/07/2016.

»Arsat (2014C). Instituciones del sector espacial de la latinoamérica analizaron en Bariloche posibles vías de colaboración regional, s/f. En: http://www.arsat.com. ar/wp-content/uploads/2014/12/INSTITUCIONES-DEL-SECTOR-ESPACIAL-DELATINOAM\%C3\%89RICA.pdf. Consultado el 01/08/2016.

»CanalAr (2006). “Arsat y Nahuelsat más cerca de la Integración”, 25 de octubre. En: http://www.canal-ar.com.ar/Nota.asp?ld=3764. Consultado el 08/06/2016.

»Casa Rosada (2014). “Lanzamiento del ARSAT 1, Cristina Fernández de Kirchner: Cadena Nacional”. Canal YouTube Casa Rosada, República Argentina. https:// www.youtube.com/watch?v=lolnTwkZx10. Consultado el 15/03/ 2018.

"Clarín (1997). Grupo Clarín: acuerdo con Galaxy, 14 de septiembre.

》Clarín (1996). En enero habrá conexiones con el satélite Nahuel, 15 de diciembre. En: http://edant.clarin.com/diario/96/12/15/o-02701d.htm. Consultado el 14/05/2016.

»Clarín (2012). La Cámpora ya pisa terreno de Julio De Vido, 6 de enero. En: http://www.clarin.com/politica/Campora-pisa-terreno-Julio-Vido_o_622737767. html. Consultado el 22/07/2016.

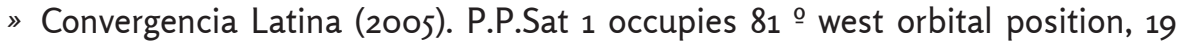
de octubre. En: http://www.convergencialatina.com/News-Detail/71306-3-51- 
P_P_Sat_1_occupies_81_west_orbital_position_?Lang=EN. Consultado el 08/06/2016.

»Convergencia Latina (2006). Arsat se quedará con Nahuelsat y elegirá mañana a SES para operar $72^{\circ}, 24$ de octubre. En: http://www.convergencialatina.com/ Nota-Desarrollo/78322-3-51-Arsat_se_quedara_con_Nahuelsat_y_elegira_ manana_a_SES_para_operar_72. Consultado el 08/06/2016.

»El Cronista (2004a). Estado le quitó a Nahuelsat la asignación para Nahuel II, 17 de agosto. En: http://www.cronista.com/impresageneral/Estado-le-quito-aNahuelsat-la-asignacion-para-Nahuel-II--20040818-0099.html. Consultado el 30/04/2016.

"El Cronista (2004b). Pekín también será parte del satélite argentino, 1 de septiembre. En: http://m.cronista.com/Mobile/nota.html?URI=/ contenidos/2004/09/02/noticia_0077.html\#. Consultado el 30/04/2016.

»El Cronista (2005a). Kirchner creará por ley la empresa nacional de satélites, 14 de julio. En: http://www.cronista.com/impresageneral/Kirchner-creara-por-ley-laempresa-nacional-de-satelites-20050715-0017.html. Consultado el 30/04/2016.

"El Cronista (2005b). Moreno dice que ArSat ya tiene cuatro interesados, 9 de agosto. En: http://www.cronista.com/impresageneral/Moreno-dice-que-ArSatya-tiene-cuatro-interesados-20050810-0052.html. Consultado el 08/06/2016.

"El Cronista (2006a). Puja con el Reino Unido por el segundo satélite argentino, 23 de febrero. En: http://www.cronista.com/impresageneral/Puja-con-el-ReinoUnido-por-el-segundo-satelite-argentino-20060224-0030.html. Consultado el o8/06/2016.

»El Cronista (2006b). Nahuelsat quiere participar en el proyecto satelital del Gobierno, 27 de abril. En: http://www.cronista.com/impresageneral/Nahuelsatquiere-participar-en-el-proyecto-satelital-del-Gobierno-20060428-0037.html. Consultado el 08/06/2016.

»El Cronista (2006c). El Gobierno ya asignó 50 millones a Arsat, 7 de junio. En: http://www.cronista.com/impresageneral/El-Gobierno-ya-asigno-los-50millones-de-Arsat-20060608-006o.html. Consultado el 30/04/2016

»El Cronista (2006d). El Estado, a punto de controlar todo el negocio satelital argentino, 23 de octubre. En: http://www.cronista.com/ impresageneral/El-Estado-a-punto-de-controlar-todo-el-negocio-satelitalargentino-20061024-0063.html. Contulado el 15/03/2017.

»El Cronista (2006e). ArSat elige hoy el proveedor que reemplazará el satélite Nahuel 1, 24 de octubre. En: http://www.cronista.com/impresageneral/ArSatelige-hoy-el-proveedor-que-reemplazara-el-satelite-Nahuel-1-20061025-0039. html. Consultado el 11/06/2016.

»Embajada de EEUU (2006). Embassy supports proposed IDB loan to Argentina for remote sensing satellite project, 27 de junio. Cable desde Buenos Aires para Department of the Treasury, National Security Council, RUEAHQA OSAF, Secretary of Defense, Secretary of State, United States Secretary of the Navy, United States Southern Command (Miami). WikiLeaks. En: http://wikileaks. org/plusd/cables/o6BUENOSAIRES1442_a.html. Consultado el 13/06/2016.

»Fernández, C. (2015). ‘El futuro ha llegado', afirmó la Presidenta tras la puesta en órbita del Arsat-2. Casa Rosada, Presidencia de la Nación, 30 de septiembre. En: http://www.casarosada.gob.ar/informacion/archivo/29108-el-futuro-hallegado-afirmo-la-presidenta-tras-la-puesta-en-orbita-del-arsat-2. Consultado el 01/08/2016. 
» Fontanals, G. (2014). Mercado e política no setor das telecomunicações móveis na Argentina. Oligopólio e intervenção estatal, Eptic Online, vol. 16, núm. 2, pp. 22-49. En: http://www.seer.ufs.br/index.php/eptic/article/download/2274/1952. Consultado el 25/07/2016.

»Fuks, M. (2013). La telefonía móvil habría facturado más de $\$ 45.000$ millones en el 2012, Río Negro, Suplemento Pulso, 6 de enero. En: http://www.rionegro. com.ar/pulso/la-telefonia-movil-habria-facturado-mas-de-AQRN_1041968. Consultado el 25/07/2016.

"Infobae (2004). El Nahuel II buscaría ayuda económica a través de la Bolsa, 6 de abril. En: http://www.infobae.com/2004/04/06/106746-el-nahuel-ii-buscariaayuda-economica-traves-la-bolsa/. Consultado el 04/05/2016.

" Krakowiak, F. (2013). Una escala antes de la puesta en órbita, Página/12, 28 de septiembre. En: www.pagina12.com.ar/diario/economia/2-230064-2013-09-28. html. Consultado el 16/07/2016.

"Naishtat, Silvia (2006). Por un peso, el Estado se hará cargo de NahuelSat, Clarín, 24 de octubre. En. http://edant.clarin.com/diario/2006/10/24/elpais/ p-01601.htm. Consultado en 21/05/2016.

» Rus, G. (2017). No es prioridad del gobierno cumplir la ley, Página/12, 9 de enero.

» Rus, G. (2018). Entrevista realizada por Daniel Blinder. Buenos Aires, 5 de abril.

"Satellite Industry Association (2015). State of Satellite Industry Report. September 2015. En: http://www.sia.org/wp-content/uploads/2015/o6/Mktg15SSIR-2015-FINAL-Compressed.pdf. Consultado el 02/05/2016.

"SES Global (2001). SES Global finalise l'acquisition de GE Americom pour 4,3 milliards de USD et devient le numéro un des opérateurs de satellites mondiaux (Comunicado de prensa), 12 de noviembre. En: http://paperjam. lu/communique/ses-global-finalise-lacquisition-de-ge-americom-pour-43milliards-de-usd-et-devient-le. Consultado el 17/10/2016.

»Telam (2012). Telecomunicaciones: interés de un gigante chino en el mercado argentino de telefonía móvil, 27 de septiembre. En: http://www.telam.com.ar/ nota/39246/. Consultado el 25/07/2016.

" The Independent (2017). There's a parking crisis in space - and you should be worried about it, 4 de octubre. En: https://www.independent.co.uk/ news/science/space-parking-space-nasa-telecom-satellites-a7981191.html. Consultado el 27/03/2018.

" Tycz, T. (2000a). Williams Communications, Inc.: Application for Modification of Earth Station License. W4 Communications Corp.: Application to Operate a 4.8-meter Ku-band Fixed Earth Station for the Provision of Digital Data, Audio, and Video Services via ALSAT and Nahuel C Satellites. Order, Federal Communications Commission, DA oo-663, 23 de marzo.

»Tycz, T. (200ob). GE AMERICAN COMMUNICATIONS, INC. Application for Authority to Launch and Operate a Replacement $\mathrm{C} / \mathrm{Ku}$ Hybrid Fixed Satellite Service Space Station at $72^{\circ}$ W.L.. Memorandum Opinion, Order and Authorization, Federal Communications Commission, DA 00-2305, 12 de octubre.

» United States Department of Commerce (1995). Argentina - Telecom. Equip. And Services, International Trade Administration, Market Research Reports, 15 de diciembre. 
»Visión 7 (2015). Discurso pronunciado por Cristina Fernández de Kirchner en el Ministerio de Ciencia, Tecnología e Innovación Productiva. Buenos Aires, 6 de Noviembre de 2015. Canal YouTube: TV Pública - Canal 7, República Argentina. En: https://www.youtube.com/watch?v=vVSbQvi8Pk4. Consultado el 15/03/2018.

\section{Daniel Blinder / dblinder@unsam.edu.ar}

Licenciado en Ciencia Política y Doctor en Ciencias Sociales, Universidad de Buenos Aires. Profesor e investigador del Centro de Estudios de Historia de la Ciencia y la Técnica, Universidad Nacional de San Martín. Especialista en Estudios Internacionales y Geopolítica.

\section{Diego Hurtado de Mendoza / dhurtado@unsam.edu.ar}

Licenciado y Doctor en Física, Universidad de Buenos Aires. Historiador de la ciencia y la tecnología. Profesor e investigador del Centro de Estudios de Historia de la Ciencia y la Técnica, Universidad Nacional de San Martín. Ex Presidente de la Autoridad Regulatoria Nuclear. 